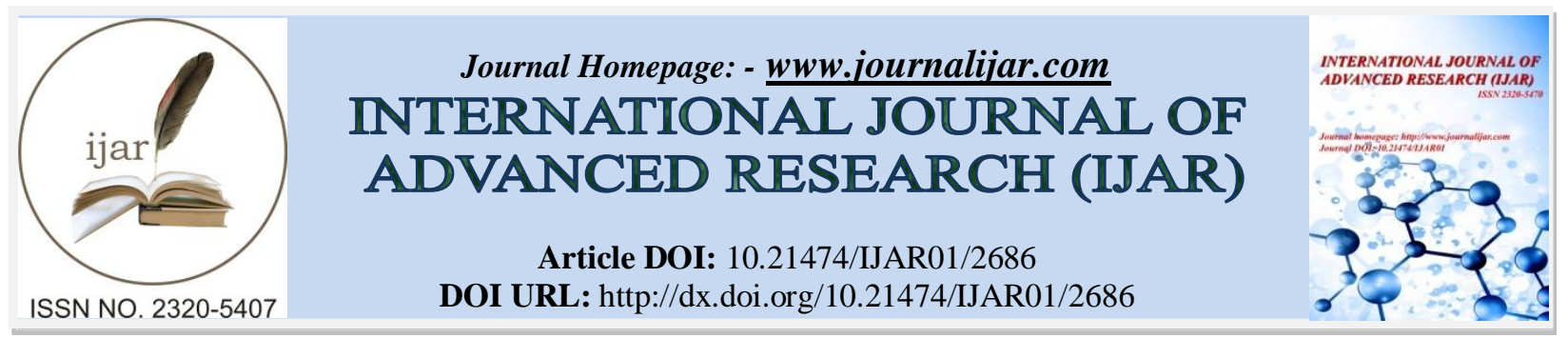

RESEARCH ARTICLE

\title{
EVALUATION OF COGNITIVE FUNCTIONS IN CHRONIC HCV ELDERLY PATIENTS.
}

\section{Sekina Ismail Ahmed (MD) ${ }^{1}$, Perihan El Sayed Salem (MD) ${ }^{2}$, Soha Abd Elatif Ahmed (MD) ${ }^{3}$ and Sara Taha} Abd Elfatah (MS) ${ }^{4}$.

1. Professor of Internal Medicine, Geriatric Department, Faculty of Medicine, Alexandria University, Alexandria, Egypt.

2. Assistant Professor of Internal Medicine, Hepatobiliary Department, Faculty of Medicine, Alexandria University, Alexandria, Egypt.

3. Assistant Professor of Neuropsychiatry, Neuropsychiatry Department, Faculty of Medicine, Alexandria University, Alexandria, Egypt.

4. Specialist of internal Medicine, Alexandria Fever Hospital, Alexandria, Egypt.

\section{Manuscript Info}

Manuscript History

Received: $x x x x x x x x x x x x x x x x$

Final Accepted: $x \times x x x x x x x x x$

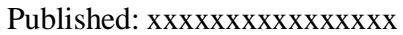

Key words:-

HCV elderly, cognitive impairment, depression, anxiety, neuropsychological tests.

\section{Abstract}

Cognitive impairment is a decline in thinking, knowing, remembering, judging, problem solving, imagination, perception, and planning. Hepatitis C Virus (HCV) is a neurovirulent virus which induces cognitive dysfunction both directly and indirectly. The present study aimed to evaluate cognitive functions in elderly patients with chronic $\mathrm{HCV}$ infection. All subjects included in the study underwent neuropsychological assessment using Mini Mental State Examination (MMSE), Wechsler Intelligence Adult Scale (WIAS) tests, Hamilton Depression Rating Scale (HAM-D) and Hamilton Anxiety Rating Scale (HAM-A). An evident low score was reported among HCV elderly patients regarding MMSE and WIAS tests in comparison to normal control subjects. On the other hand, an evident high score was reported among HCV elderly patients regarding HAM-D and HAM-A tests in comparison to normal control subjects. HCV patients showed significant cognitive impairment with psychiatric disorders including depression and anxiety in comparison to normal control subjects.

Copy Right, IJAR, 2016,. All rights reserved.

\section{Introduction:-}

Cognition is a term referring to the mental processes involved in gaining knowledge and comprehension. These processes include thinking, knowing, remembering, judging, and problem solving. These are higher level functions of the brain and encompass language, imagination, perception, and planning. (Blomberg O, 2011)

Cognitive impairment is defined as a decline in at least one of the following domains: short term memory, attention, orientation, judgment, problem solving skills, and visuospatial skills. (Winblad B et al., 2004) Most persons experience a modest increase in memory problems as they get older, particularly with regard to the ability to remember relatively recent experiences. There is impaired ability to accumulate new information and to retrieve existing information from memory, with decline in the ability to store new information once it is learned. (Masunaga $\mathrm{H}$ and Horn J, 2001) 
Hepatitis C virus (HCV) infection is a serious global health problem that affects up to 180 million people worldwide, with estimated 3-4 million people infected every year. HCV causes chronic hepatitis which can eventually leads to cirrhosis and HCC. (Berenguer M et al., 2001) The highest prevalence has been reported from Egypt (15\%-20\%), where the prevalence of infection increases steadily with age. (Abd El-Wahab E et al., 2014)

In addition to the physical problems associated with chronic HCV, there is a high rate of psychiatric co morbidity, with up to $40 \%$ of $\mathrm{HCV}$ infected persons meeting diagnostic criteria for a concurrent, active psychiatric disorder. Depression and anxiety are the most common comorbid psychiatric disorders, with a prevalence ranging from 28$50 \%$ and $18-41 \%$ respectively. (Golden $\mathrm{J}$ et al., 2005)

It is well known that advanced forms of chronic liver disease are accompanied by overt cognitive deficit; hepatic encephalopathy (HE). Researchers and clinicians have become increasingly aware of a group of HCV patients with mild liver disease that present with a less overt pattern of neuropsychological impairment; minimal hepatic encephalopathy (MHE). (Binesh N et al., 2006)

$\mathrm{HCV}$ is a member of the Flaviviridae, which is one of neurovirulent viruses. The etiology of cognitive dysfunction exhibited by patients with HCV is unknown; however, there was increasing evidence suggests that there may be a direct effect of the virus on brain function via a "Trojan horse" mechanism. (Forton DM et al., 2002) The "Trojan horse" hypothesis proposes that infected monocytes migrate to the brain and replace microglia cells, which are located predominantly in the cerebral white matter. They are known to release excitatory amino acids that can induce neuronal cell death via excitotoxicity, and they can exert a neuromodulatory role through the release of neurotoxins and other neurochemicals. (Weissenborn $\mathrm{K}$ et al., 2006)

Also, recent study suggested that HCV may disrupt the blood brain barrier (BBB) integrity. In chronically infected $\mathrm{HCV}$ patients, the virus produces approximately 1012 viral particles per day, which are released into the blood stream and encounter endothelial cells of BBB. Direct viral infection of BBB endothelial cells may occur, resulting in apoptosis and BBB breakdown that could allow entry of inflammatory cytokines, viral particles and other neurotoxic substances. (Fletcher NF and Mc Keating JA, 2012)

Moreover, secondary effects of HCV include activation of the immune system as there is increasing appreciation of a possible role of cytokines mediated cognitive dysfunction. (Wilson CJ et al., 2002) It is well known that cytokines are regulated in cascades which involve positive and negative feedback loops within the brain. Once an individual is infected with HCV, cytokines such as interleukin (IL)-2, IL-4, IL-10, interferon-gamma (IFN- $\gamma$ ), interferon-alpha (IFN- $\alpha$ ) and tumor necrosis factor alpha (TNF- $\alpha$ ) may cross BBB and affect brain functions. (Huckans M et al., 2014)

Tests for assessment of cognitive functions are multiple including Mini Mental State Examination (MMSE) which is the most widely used cognitive test, (Tuijl JP et al., 2012) Wechsler Intelligence Adult Scale (WIAS) tests including; digit span forward and backward tests. (Wisdom NM et al., 2012) Moreover, Hamilton Depression Rating Scale (HAM-D) and Hamilton Anxiety Rating Scale (HAM-A) are satisfactory tools for screening of depression and anxiety. (Vaccarino AL et al., 2008)

\section{Aim of work:-}

The present work aimed to evaluate cognitive functions in chronic HCV elderly patients. Also, to compare their performance with that of $\mathrm{HCV}$ negative elderly subjects.

\section{Methods:-}

The present study included $50 \mathrm{HCV}$ elderly patients aged 65 years or more (Group I) who are presented to Hepatobiliary and Geriatric outpatient clinics, Alexandria Main University Hospital. Also, 25 HCV negative age and sex matched subjects were included as a control group (Group II), to obtain normal range of laboratory and neuropsychological tests.

Patients were diagnosed as chronic HCV by testing for HCV antibodies and HCV PCR. Also, the studied HCV patients were compensated (Child A) according to Child Pugh classification.

Exclusion criteria included: detectable hepatitis B surface antigen (HBsAg), patients on anti HCV therapy, decompensated liver disease (Child B/C), hepatocellular carcinoma (HCC), patients with renal diseases, alcohol use, 
psychiatric disorders causing cognitive dysfunction (as dementia; delirium; depression and bipolar disorders), illiteracy and intellectual disabilities, patients with diabetes mellitus and patients with cerebrovascular disorders.

All patients were subjected to detailed history taking and full clinical assessment. Also, biochemical studies were done including: complete blood count (CBC), liver function tests (AST, ALT, serum albumin, total serum bilirubin and prothrombin time) and viral markers (anti-HCV antibodies and HCV PCR for HCV antibodies positive patients, HBs Ag). Neuropsychological assessment was done using the following tests:

Mini-mental state examination (MMSE): (Tuijl JP et al., 2012):-

It is a screening tool that provides a brief and objective measure of cognitive function (registration, attention and calculation, recall, language, ability to follow simple commands and orientation). MMSE score is useful in quantitatively estimating the severity of cognitive impairment and in serially documenting cognitive changes.

The MMSE consists of a variety of questions with a maximum score of 30 points and can be administered in 5-10 minutes. The questions are grouped into seven categories, each representing a different cognitive domain or function: 1.Orientation to time (5 points), 2. Orientation to place (5 points), 3.Registration of three words ( 3 points), 4.Attention and calculation (5 points), 5.Recall of three words (3 points), 6.Language (8 points), and 7.Visual construction (1 point).

Any score greater than or equal to 25 points (out of 30) indicates a normal cognition. Below this, scores can indicate severe ( $\leq 9$ points), moderate (10-18 points) or mild (19-24 points) cognitive impairment.

Wechsler intelligence adult scale (WIAS): (Wisdom NM et al., 2012):-

It includes digit span forward and backward tests which used to investigate working memory. Digit span test consists of telling the person to listen carefully to a series of numbers as he will repeat them back in the same order.

The first series is three numbers, each number is said in a monotone voice and one second apart, the person repeats those numbers. Next series is four numbers, again, the individual repeats those back. Continue in the same manner by increasing the series of numbers to five. This test can be varied by asking the person to repeat the numbers backwards by starting with the last number and going to the first number. This is called the digit span backward test.

Sources vary about the cutoff for a normal score, but the inability to accurately repeat less than five numbers seems indicative of a concern.

Hamilton depression rating scale (HAM-D): (Vaccarino AL et al., 2008):-

It is a useful way of determining patient's level of depression; it lists 21 items and takes 15-20 minutes to complete. HAM-D scoring interpretation is: No depression: a score of 0-7, Mild depression: a score of 8-13, Moderate depression: a score of 14-18, Severe depression: a score of 19-22, Very severe depression: a score of greater than 23.

Hamilton anxiety rating scale (HAM-A): (Vaccarino AL et al., 2008):-

HAM-A quantifies the severity of anxiety, it consists of 14 items each item is rated on a 5-point scale, ranging from 0 (not present) to 4 (severe). HAM-A scoring interpretation is: Mild anxiety: 14-17, Moderate anxiety: 18-24, Severe anxiety: 25-30.

All subjects included in the study signed an informed written consent before joining the study.

\section{Results:-}

Demographic data:-

Age showed a close median of 67 years and 69 years in Group I and Group II respectively. Regarding sex, males predominated females in both groups.

Different studied laboratory parameters:-

Complete blood count (CBC): 
Table (1) showed comparison between the two studied groups according to CBC. Serum HB level showed a close median of $11.55 \mathrm{~g} / \mathrm{dl}$ and $11.8 \mathrm{~g} / \mathrm{dl}$ in Group I and Group II respectively. Also, WBCs had a close median of 5.75 $\left(10^{3} / \mathrm{mm}^{3}\right)$ and $5.0\left(10^{3} / \mathrm{mm}^{3}\right)$ in Group I and Group II respectively. No statistical significant difference was reported among both groups regarding HB level and WBCs. On other hand, a statistical significant difference was reported between the two studied groups as regards platelets count, where the mean value was $168.50\left(10^{3} / \mathrm{mm}^{3}\right)$ and $206.0\left(10^{3} / \mathrm{mm}^{3}\right)$ in Group I and Group II respectively $(\mathrm{P}=0.001)$.

\section{Liver function tests:-}

showed a significant increase in the serum level of liver enzymes (AST, ALT); total serum bilirubin and prothrombin time in Group I patients with HCV related chronic liver disease in comparison to Group II normal control subjects, with a statistical significant difference between both groups.

On the other hand, a significant decrease in the mean of serum albumin level was observed among Group I HCV patients in comparison to Group II normal control subjects $(3.88 \pm 0.38 \mathrm{~g} / \mathrm{dl}$ and $4.11 \pm 0.34 \mathrm{~g} / \mathrm{dl}$ respectively) with a statistical significant difference between both groups $(\mathrm{P}=0.012)$.

\section{Quantitative HCV-PCR in Group I HCV patients:-}

It showed a mean of $640.54 \pm 838.0 \times 10^{3}(\mathrm{IU} / \mathrm{ml})$.

\section{Neuropsychological tests:-}

Table (3) showed an evident low score among Group I HCV patients regarding MMSE, digit span forward and backward tests in comparison to Group II normal control subjects, with a statistical significant difference between both studied groups $(\mathrm{p}<0.001)$. This means that $\mathrm{HCV}$ patients had significant cognitive impairment as regards orientation, registration, attention, recall, language and calculation in comparison to normal HCV negative age and sex matched control subjects.

On the other hand, an evident high score was reported among Group I HCV patients regarding HAM-D and HAMA tests in comparison to Group II normal control subjects, with a statistical significant difference between both studied groups $(\mathrm{p}<0.001)$. This means that HCV patients had psychiatric disorders including depression and anxiety in comparison to normal HCV negative age and sex matched control subjects.

\section{Correlation between neuropsychological tests and different studied parameters:-}

HCV PCR and liver enzymes (AST, ALT) showed negative correlation with MMSE; digit span tests and positive correlation with both HAM-A and HAM-D tests. On the other hand, no significant correlation was observed between other liver function tests (total serum bilirubin, serum albumin, prothrombin time) and different neuropsychological tests. Table (4)

Table 1:- Comparison between the two studied groups according to CBC.

\begin{tabular}{|c|c|c|c|c|}
\hline & $\begin{array}{l}\text { HCV } \\
(n=50)\end{array}$ & $\begin{array}{l}\text { Control } \\
(\mathrm{n}=25)\end{array}$ & Test of Sig. & $\mathbf{p}$ \\
\hline \multicolumn{5}{|l|}{ HB (g/dl) } \\
\hline Min.-Max. & $7.90-15.60$ & $10.0-14.0$ & \multirow[t]{3}{*}{$\mathrm{t}=1.455$} & \multirow[t]{3}{*}{0.150} \\
\hline Mean \pm SD. & $11.42 \pm 1.56$ & $11.83 \pm 0.90$ & & \\
\hline Median & 11.55 & 11.80 & & \\
\hline WBCs $\left(10^{3} / \mathrm{mm}^{3}\right)$ & & & $\mathrm{Z}=1.585$ & 0.113 \\
\hline Min.-Max. & $2.20-10.65$ & $3.90-7.80$ & & \\
\hline Mean \pm SD. & $6.17 \pm 1.94$ & $5.43 \pm 1.37$ & & \\
\hline Median & 5.75 & 5.0 & & \\
\hline Platelets $\left(10^{3} / \mathrm{mm}^{3}\right)$ & & & $\mathrm{Z}=3.339^{*}$ & $0.001^{*}$ \\
\hline Min.-Max. & $82.0-324.0$ & $160.0-267.0$ & & \\
\hline Mean \pm SD. & $180.70 \pm 57.85$ & $212.64 \pm 26.61$ & & \\
\hline Median & 168.50 & 206.0 & & \\
\hline
\end{tabular}

$\mathrm{Z}$ : Z for Mann Whitney test $\quad$ *: Statistically significant at $\mathrm{p} \leq 0.05$

$\mathrm{t}$ : Student t-test 
Table 2:- Comparison between the two studied groups according to liver function tests.

\begin{tabular}{|c|c|c|c|c|}
\hline & $\begin{array}{l}\text { HCV } \\
(n=50)\end{array}$ & $\begin{array}{l}\text { Control } \\
(n=25)\end{array}$ & Test of Sig. & $\mathbf{p}$ \\
\hline \multicolumn{5}{|l|}{ AST (U/I) } \\
\hline Min.-Max. & 25.01682 .0 & $12.0-45.0$ & \multirow[t]{3}{*}{$\mathrm{Z}=6.745^{*}$} & \multirow[t]{3}{*}{$<0.001$} \\
\hline Mean \pm SD. & $166.20 \pm 241.69$ & $23.28 \pm 8.33$ & & \\
\hline Median & 108.50 & 23.0 & & \\
\hline \multicolumn{5}{|l|}{ ALT (U/I) } \\
\hline Min.-Max. & $18.0-880.0$ & $10.0-40.0$ & \multirow[t]{3}{*}{$\mathrm{Z}=6.224^{*}$} & \multirow[t]{3}{*}{$<0.001$} \\
\hline Mean \pm SD. & $129.70 \pm 135.85$ & $20.20 \pm 7.95$ & & \\
\hline Median & 88.50 & 19.0 & & \\
\hline \multicolumn{5}{|c|}{$\begin{array}{l}\text { Total } \\
(\mathrm{mg} / \mathrm{dl})\end{array}$} \\
\hline Min.-Max. & $0.40-1.90$ & $0.30-0.80$ & \multirow[t]{3}{*}{$Z=5.950^{*}$} & \multirow[t]{3}{*}{$<0.001$} \\
\hline Mean \pm SD. & $1.23 \pm 0.43$ & $0.55 \pm 0.15$ & & \\
\hline Median & 1.30 & 0.50 & & \\
\hline \multicolumn{5}{|l|}{ PT (seconds) } \\
\hline Min.-Max. & $10.70-14.0$ & $10.80-13.0$ & \multirow[t]{3}{*}{$\mathrm{t}=2.711^{*}$} & \multirow[t]{3}{*}{$0.008^{*}$} \\
\hline Mean \pm SD. & $12.35 \pm 0.93$ & $11.78 \pm 0.73$ & & \\
\hline Median & 12.55 & 11.70 & & \\
\hline \multicolumn{5}{|l|}{ Albumin (g/dl) } \\
\hline Min.-Max. & $3.10-4.90$ & $3.50-4.90$ & \multirow[t]{3}{*}{$\mathrm{t}=2.565^{*}$} & \multirow[t]{3}{*}{$0.012^{*}$} \\
\hline Mean \pm SD. & $3.88 \pm 0.38$ & $4.11 \pm 0.34$ & & \\
\hline Median & 3.80 & 4.10 & & \\
\hline
\end{tabular}

Z: Z for Mann Whitney test *: Statistically significant at $\mathrm{p} \leq 0.05 \mathrm{t}$ : Student t-test

Table 3:- Comparison between the two studied groups according to neuropsychological tests.

\begin{tabular}{|c|c|c|c|c|}
\hline & $\begin{array}{l}\text { HCV } \\
(n=50)\end{array}$ & $\begin{array}{l}\text { Control } \\
(n=25)\end{array}$ & Test of Sig. & $\mathbf{p}$ \\
\hline \multicolumn{5}{|l|}{ MMSE } \\
\hline Min.-Max. & $11.0-27.0$ & $25.0-33.0$ & \multirow[t]{3}{*}{$\mathrm{t}=18.238^{*}$} & \multirow[t]{3}{*}{$<0.001$} \\
\hline Mean \pm SD. & $18.06 \pm 4.0$ & $30.64 \pm 1.98$ & & \\
\hline Median & 18.0 & 31.0 & & \\
\hline \multicolumn{5}{|c|}{ Digit span forward } \\
\hline Min.-Max. & $2.0-5.0$ & $4.0-6.0$ & \multirow[t]{3}{*}{$\mathrm{t}=11.563^{*}$} & \multirow[t]{3}{*}{$<0.001$} \\
\hline Mean \pm SD. & $3.36 \pm 0.72$ & $5.32 \pm 0.63$ & & \\
\hline Median & 3.0 & 5.0 & & \\
\hline \multicolumn{5}{|c|}{ Digit span backward } \\
\hline Min.-Max. & $0.0-3.0$ & $3.0-5.0$ & \multirow[t]{3}{*}{$\mathrm{Z}=7.129^{*}$} & \multirow[t]{3}{*}{$<0.001$} \\
\hline Mean \pm SD. & $2.18 \pm 0.85$ & $4.24 \pm 0.52$ & & \\
\hline Median & 2.0 & 4.0 & & \\
\hline \multicolumn{5}{|l|}{ HAM-D } \\
\hline Min.-Max. & $9.0-26.0$ & $5.0-12.0$ & \multirow[t]{3}{*}{$t=15.652^{*}$} & \multirow[t]{3}{*}{$<0.001$} \\
\hline Mean \pm SD. & $18.16 \pm 4.45$ & $6.76 \pm 1.83$ & & \\
\hline Median & 18.50 & 7.0 & & \\
\hline \multicolumn{5}{|l|}{ HAM-A } \\
\hline Min.-Max. & $10.0-24.0$ & $2.0-13.0$ & \multirow[t]{3}{*}{$t=15.648^{*}$} & \multirow[t]{3}{*}{$<0.001$} \\
\hline Mean \pm SD. & $18.32 \pm 3.57$ & $6.68 \pm 2.73$ & & \\
\hline Median & 18.50 & 6.0 & & \\
\hline
\end{tabular}

$\mathrm{Z}$ : Z for Mann Whitney test $\quad$ *: Statistically significant at $\mathrm{p} \leq 0.05$

$\mathrm{t}$ : Student t-test 
Table 4:- Correlation between neuropsychological tests and different studied parameters.

\begin{tabular}{|c|c|c|c|c|c|c|}
\hline & & \multicolumn{5}{|c|}{ Neurological exam } \\
\hline & & $\begin{array}{l}\text { Digit span } \\
\text { forward }\end{array}$ & $\begin{array}{l}\text { Digit span } \\
\text { backward }\end{array}$ & MMS & НАМ-А & HAM-D \\
\hline \multirow[t]{2}{*}{ HCV PCR } & $\mathbf{r}$ & -0.156 & -0.023 & -0.262 & $0.307^{*}$ & $0.361^{*}$ \\
\hline & $\mathbf{p}$ & 0.281 & 0.876 & 0.066 & $0.030^{*}$ & $0.010^{*}$ \\
\hline \multirow[t]{2}{*}{ AST } & $\mathbf{r}$ & -0.195 & -0.162 & -0.227 & 0.203 & $0.317^{*}$ \\
\hline & $\mathbf{p}$ & 0.176 & 0.261 & 0.114 & 0.158 & $0.025^{*}$ \\
\hline \multirow[t]{2}{*}{ ALT } & $\mathbf{r}$ & -0.175 & -0.117 & -0.209 & 0.260 & $0.361^{*}$ \\
\hline & $\mathbf{p}$ & 0.225 & 0.419 & 0.144 & 0.069 & $0.010^{*}$ \\
\hline \multirow[t]{2}{*}{ Total bilirubin } & $\mathbf{r}$ & -0.011 & 0.244 & 0.005 & -0.008 & 0.003 \\
\hline & $\mathbf{p}$ & 0.939 & 0.087 & 0.972 & 0.955 & 0.983 \\
\hline \multirow[t]{2}{*}{ PT } & $\mathbf{r}$ & -0.099 & -0.201 & -0.060 & 0.102 & 0.162 \\
\hline & $\mathbf{p}$ & 0.493 & 0.162 & 0.681 & 0.480 & 0.260 \\
\hline \multirow[t]{2}{*}{ Albumin } & $\mathbf{r}$ & -0.095 & -0.066 & 0.091 & -0.150 & -0.224 \\
\hline & $\mathbf{p}$ & 0.511 & 0.650 & 0.530 & 0.300 & 0.117 \\
\hline
\end{tabular}

r: Pearson coefficient

*: Statistically sig

\section{Discussion:-}

Cognitive impairment has been well documented in patients with HCV related chronic liver disease and cirrhosis, however; there is growing evidence that there are fundamental cognitive deficits in HCV patients prior to the development of cirrhosis. (Shawcross D and Jalan R, 2005) Cognitive problems may influence medical care, as cognitively impaired patients may fail to remember (or remember incorrectly) important details about their disease, treatment regimen, and/or physicians' recommendations. They may experience difficulties performing household and job duties as efficiently and accurately as before. (Back Madruga C et al., 2003)

High levels of general psychological distress and mood disturbance, especially depression and anxiety are also apparent in persons with chronic HCV. (Yovtcheva SP et al., 2001)

The increasing life expectancy in developed countries and the long standing course of chronic HCV infection make it likely that physicians will face a growing number of elderly patients with HCV related chronic liver diseases in the next 10-20 years. So, there is increasing interest in the combined effect of aging and cognitive deficits in HCV patients. (Thabut D et al., 2006)

In our study, MMSE; digit span forward and backward tests had evident low medians in Group I HCV patients in comparison to Group II normal control subjects, with a statistical significant difference between both studied groups $(\mathrm{p}<0.001)$. Thus, in our study chronic HCV patients performed significantly worse than healthy controls in cognitive function tests.

The specific role of $\mathrm{HCV}$ in causing cerebral function abnormalities was reported where cerebral metabolic abnormalities in the frontal white matter and basal ganglia of HCV infected patients were detected using proton magnetic resonance spectroscopy (MRS); these alterations were not present in either controls or patients with HBV infection. (Forton DM et al., 2001) In the following year, the same group showed significant impairment in the working memory and concentration of $27 \mathrm{HCV}$ infected patients with active viral replication compared to 20 controls and 16 anti-HCV positive but HCV RNA negative patients. (Forton DM et al., 2002)

Another study confirmed the presence of minor attention deficits and impairment in verbal learning ability in HCV patients. (Mc Andrews MP et al., 2005) More recently, HCV PCR positive patients had significantly poorer scores in the areas of memory, auditory recognition and sustained attention compared to healthy controls. (Lowry D et al., 2010) In another study, the authors found that $33 \%$ of $\mathrm{HCV}$ patients had impaired verbal recall and working memory, moreover, impairment was not related to liver fibrosis. (Fontana RJ et al., 2005)

Again, Hilsabeck RC et al showed deficits in attention, learning, psychomotor speed, and mental flexibility, where greater impairment was associated with greater fibrosis stage. (Hilsabeck RC et al., 2002) On contrast to our results, 
some researchers showed normal neuropsychiatric performance in HCV patients with normal hepatic function. (Soogoor M et al., 2006)

Regarding HAM-D and HAM-A tests, Group I HCV patients showed high scores in comparison to Group II normal control subjects with a statistical significant difference between both studied groups. This means that HCV patients had psychiatric disorders including depression and anxiety in comparison to normal HCV negative age and sex matched control subjects.

In agreement with our results, moderate to severe fatigue, high level of depression and anxiety were reported among studied HCV patients than the healthy controls. (Weissenborn K et al., 2004) Also, in a retrospective chart review of 33.824 HCV patients, $86 \%$ had at least 1 past or present psychiatric illness or substances abuse problem. Depression was found in up to $49.5 \%$ of this sample, and alcohol/drug use disorders were identified in $77.6 \%$ and $69.4 \%$ of the sample respectively. (El Serag HB et al., 2002)

Moreover, Dwight MM et al., 2000 found a 28\% prevalence of depressive disorders among 50 HCV patients who were evaluated with standardized rating scales. Similarly, Lee DH et al., 1997 in a retrospective chart review of 359 HCV patients who had not received interferon therapy found that $24 \%$ of the studied patients had depression. Also, in agreement with our study Hunt CM et al., 1997 prospectively evaluated 28 subjects with HCV and found $30 \%$ prevalence of depression.

In our study, HCV PCR and liver enzymes (AST, ALT) showed negative correlation with MMSE; digit span tests and positive correlation with both HAM-A and HAM-D tests. On the other hand, no significant correlation was observed between other liver function tests (total serum bilirubin, serum albumin, prothrombin time) and different neuropsychological tests.

\section{Conclusion:-}

1. Chronic HCV infection is accompanied by cognitive dysfunction even in the absence of overt liver cirrhosis suggesting direct action of $\mathrm{HCV}$ on the brain.

2. Neuropsychological tests including MMSE, digit span forward and backward tests are considered as satisfactory screening tools that provide assessment for cognitive function and working memory.

3. Depression and anxiety are common psychiatric disorders among HCV patients. Moreover, HAM-D and HAMA tests are adequate tools for their diagnosis.

\section{References:-}

1. Abd El-Wahab E, Mikheal A, Sidkey F and Shatat HZ (2014). Factors Associated with Hepatitis C Infection among Chronic HCV Egyptian Patients. Iran Journal of Public Health 43(11): 1510-1518.

2. Back Madruga C, Fontana R, Bieliauskas L (2003). Predictors of cognitive impairment in chronic hepatitis C patients entering the HALT-C trial. Journal of the International Neuropsychological Society 9: 245-246.

3. Berenguer M, Lopez Labrador FX and Wright TL (2001). Hepatitis C and liver transplantation. Journal of Hepatology 35: 666-678.

4. Binesh N, Huda A, Thomas MA, Wyckoff N, Bugbee M and Han S (2006). Hepatic Encephalopathy: A Neurochemical Neuroanatomical and Neuropsychological Study. Journal of Applied Clinical Medical Physics 7: 86-96.

5. Blomberg O (2011). Concepts of cognition for cognitive engineering. International Journal of Aviation Psychology 21: 85-104.

6. Dwight MM, Kowdley KV, Russo JE, Ciechanowski PS, Larson AM and Katon WJ (2000). Depression, fatigue, and functional disability in patients with chronic hepatitis C. Journal of Psychosomatic Research 49(5): 311-317.

7. El-Serag HB, Kunik M, Richardson P and Rabeneck L (2002). Psychiatric disorders among veterans with hepatitis C infection. Gastroenterology 123: 476-482.

8. Fletcher NF and Mc Keating JA (2012). Hepatitis C Virus and the Brain. Journal of Viral Hepatitis 19: $301-306$.

9. Fontana RJ, Bieliauskas LA, Back-Madruga C, Lindsay KL, Kronfol Z, Lok AS and Padmanabhan L (2005). Cognitive function in hepatitis C patients with advanced fibrosis enrolled in the HALT-C trial. Journal of Hepatology 43: 614-622. 
10. Forton DM, Allsop JM, Main J, Foster GR, Thomas HC and Taylor-Robinson SD (2001). Evidence for a cerebral effect of the hepatitis C virus. Lancet 358: 38-39.

11. Forton DM, Thomas HC, Murphy CA, Allsop JM, Foster GR, Main J, Wesnes KA and Taylor-Robinson SD (2002) . Hepatitis C and Cognitive Impairment in a Cohort of Patients with Mild Liver Disease. Hepatology 35(2): 433- 439.

12. Golden J, O'Dwyer AM and Conroy RM (2005). Depression and anxiety in patients with hepatitis C: prevalence, detection rates and risk factors. General Hospital Psychiatry 27: 431-438.

13. Hilsabeck RC, Perry W and Hassanein TI (2002). Neuropsychological Impairment in Patients with Chronic Hepatitis C. Hepatology 35: 440-446.

14. Huckans M, Fuller BE, Olavarria H, Sasaki AW, Chang M, Flora KD, Kolessar M, Kriz D, Anderson JR, Vandenbark AA and Loftis JM (2014). Multi-analyte profile analysis of plasma immune proteins: altered expression of peripheral immune factors is associated with neuropsychiatric symptom severity in adults with and without chronic hepatitis C virus infection. Brain Behavior 4(2): 123-142.

15. Hunt CM, Dominitz JA and Philips Bute B (1997). Effect of interferon alfa treatment of chronic hepatitis C on health related quality of life. Digestive Diseases and Sciences 42(12): 2482-2486.

16. Lee DH, Jamal H and Regenstein FG (1997). Morbidity of chronic hepatitis C as seen in a tertiary care medical center. Digestive Diseases and Sciences 42(1): 186-191.

17. Lowry D, Coughlan B, McCarthy $\mathbf{O}$ and Crowe J (2010). Investigating health-related quality of life, mood and neuropsychological test performance in a homogeneous cohort of Irish female hepatitis $\mathrm{C}$ patients. Journal of Viral Hepatitis 17: 352-359.

18. Masunaga $\mathbf{H}$ and Horn $\mathbf{J}$ (2001). Expertise and age related changes in components of intelligence. Psychology and Aging 16(2): 293-311.

19. Mc Andrews MP, Farcnik K, Carlen P, Damyanovich A, Mrkonjic M, Jones S and Heathcote EJ (2005). Prevalence and Significance of Neurocognitive Dysfunction in Hepatitis C in the Absence of Correlated Risk Factors. Hepatology 41(4): 801-808.

20. Shawcross D and Jalan R (2005). The pathophysiologic basis of hepatic encephalopathy: central role for ammonia and inflammation. Cell Molecular Life Science 62: 2295-2304.

21. Soogoor M, Lynn HS, Donfield SM, Gomperts E, Bell TS and Daar ES (2006). Hepatitis C virus infection and neurocognitive function. Neurology 67: 1482-1485.

22. Thabut D, Le Calvez S, Thibault V, Massard J, Munteanu M, Di Martino V, Ratziu V and Poynard T (2006). Hepatitis C in 6,865 patients 65 yr or older: a severe and neglected curable disease. American Journal of Gastroenterology 101(6): 1260-1267.

23. Tuijl JP, Scholte EM, de Craen AJM and Van der Mast RC (2012). Screening for cognitive impairment in older general hospital patients: comparison of the six item cognitive test with the Mini Mental State Examination. International journal of Geriatric Psychiatry 27: 755-762.

24. Vaccarino AL, Evans KR, Sills TL and Kalali AH (2008). Symptoms of anxiety in depression: assessment of item performance of the Hamilton Anxiety Rating Scale in patients with depression. Depression \& Anxiety 25: 1006-1013.

25. Weissenborn K, Krause J, Bokemeyer M, Hecker H, Schüler A, Ennen JC, Ahl B, Manns MP and Böker KW (2004). Hepatitis C virus infection affects the brain-evidence from psychometric studies and magnetic resonance spectroscopy. Journal of Hepatology 41: 845-851.

26. Weissenborn K, Ennen JC, Bokemeyer M, Ahl B, Wurster U, Tillmann H, Trebst C, Hecker H and Berding G (2006). Monoaminergic neurotransmission is altered in hepatitis $C$ virus infected patients with chronic fatigue and cognitive impairment. Gut 55: 1624-1630.

27. Wilson CJ, Finch CE and Cohen HJ (2002). Cytokines and cognition- the case for a head to toe inflammatory paradigm. Journal of the American Geriatrics Society 50(12): 2041-2056.

28. Winblad B, Palmer K and Kivipelto M (2004). Mild cognitive impairment beyond controversies, towards a consensus: Report of the International Working Group on Mild Cognitive Impairment. Journal of Internal Medicine 256: 240-246.

29. Wisdom NM, Mignogna J and Collins RL (2012). Variability in Wechsler Adult Intelligence Scale-IV Subtest Performance Across Age. Clinical Neuropsychology 27: 389-397.

30. Yovtcheva SP, AlyRifai M, Moles JK and Van Der Linden BJ (2001). Psychiatric comorbidity among hepatitis C-positive patients. Psychosomatics 42: 411-415. 